\title{
A ROTA DOS ESTUDOS SOBRE A COCHONILHA EM PORTUGAL E NO BRASIL NO SÉCULO XIX: CAMINHOS DESENCONTRADOS ${ }^{*}$
}

\author{
Márcia Helena Mendes Ferraz* \\ Centro Simão Mathias de Estudos em História da Ciência, Pontifícia Universidade Católica de São Paulo, Rua Caio Prado, 102, \\ 01303-000 São Paulo - SP, Brasil
}

Recebido em 22/6/06; aceito em 31/10/06; publicado na web em 28/5/07

\begin{abstract}
THE ROUTE OF THE STUDIES OF COCHINEAL IN PORTUGAL AND BRAZIL IN THE NINETEENTH CENTURY: UNCROSSED PATHS. For imparting an intense and long-lasting red to fabrics, cochineal remained in high demand during the eighteenth and nineteenth centuries. This period witnessed, accordingly, several initiatives aimed at producing the precious dye: publication of specialized texts, cultivation of the cactus and the insect from which the dye is extracted, and, also, attempts to obtain the secrets of production through espionage. The present paper analyses certain aspects of the measures adopted by the Portuguese government towards Brazil in this field. The work shows how people sought to take part in the network of cochineal production (yet they were unsuccessful most of the time).
\end{abstract}

Keywords: history of science; history of chemistry; cochineal.

Em diferentes períodos corantes vermelhos foram obtidos de diversos materiais, de origem vegetal ou animal. Os mais cobiçados pela intensidade e brilho da coloração dada aos tecidos eram obtidos de animais como o múrice (ou murex) ${ }^{1}$, molusco utilizado na Antigüidade e que dava a Púrpura de Tiro, substituído pelo quermes² durante a Idade Média. A eles se pode acrescentar a Cochonilha da Polônia e a Cochonilha da Armênia, muito procuradas no Renascimento ${ }^{3}$.

As viagens dos europeus às terras que inicialmente imaginavam ser as Índias levaram-nos a conhecer, na região então sob dominação asteca, um corante - denominado na língua nativa (nahuatl) nochetztli, ou seja, 'sangue da terra' - que também dava um esplêndido vermelho, usado pelos nativos para colorir o corpo e os dentes, além de tecidos, alimentos e paredes, e ainda para elaborar seus códices ${ }^{4}$. Os espanhóis passaram a chamá-la de grana cochinilla, em referência justamente a outra grã, um corante obtido do quermes. Ao se dar conta da importância desse material, o governo espanhol ordenou, ainda no século XVI, a busca de informações sobre como obter esse produto que, enviado à Castela, poderia gerar grandes lucros 5 . Uma ordenação de Felipe III - rei de Espanha e Portugal entre 1598-1621 - deixa clara a importância do corante ao considerá-lo : “...um dos mais caros frutos que se criam em nossas Índias Ocidentais [...], mercadoria que se equipara ao ouro e à prata" ${ }^{\text {. }}$. Dados sobre a exportação do produto e uso na Europa mostram que Felipe III tinha razão ${ }^{7}$.

Diferentes códices mexicanos estampam os processos de preparação do corante e, já na década de 1540 começam a aparecer, em espanhol, menções mais claras à produção da cochonilha - como a de Bernardino de Sahagún - mas algumas formas especiais de apresentação do produto permaneceram segredo dos nativos ${ }^{8}$. Três séculos mais tarde, continuam a sair dos prelos textos que pretendem 'desvendar' segredos da fabricação do corante, como é o caso

\#Trabalho realizado no âmbito do Projeto Temático apoiado pela FAPESP: "As complexas transformações da ciência da matéria: entre o compósito do saber antigo e a especialização moderna", coordenado por A. M. AlfonsoGoldfarb, junto ao Centro Simão Mathias de Estudos em História da Ciência - Cesima/PUCSP.

*e-mail: mhferraz@pucsp.br de Memoria sobre la naturaleza, cultivo y beneficio de la grana, de J. A. Alzate y Ramires?.

A cochonilha é um inseto parasita de certos gêneros de cactos, chamados de nopal pelos nativos habitantes da Nova Espanha ${ }^{10}$. O macho é voador, enquanto a fêmea se fixa nas palmas da planta, onde cresce e se reproduz, em um ciclo que dura cerca de 2 meses. Da carapaça dessecada da fêmea, de cor marrom-avermelhada, produz-se o corante, a partir da decocção em água ${ }^{11}$. A cochonilha - já sabiam os nativos - pode ser de dois tipos: a fina e a silvestre (que vão dar, respectivamente, segundo a denominação espanhola, a grana fina e a grana silvestre $)^{12}$. A cochonilha fina, também denominada à época de mesteca, diferenciava-se da silvestre por ser maior e estar coberta de um pó branco, de aspecto ceroso, enquanto a silvestre se cobria de uma espécie de algodão fino $^{13}$. O processo utilizado pelos indígenas consistia em 'semear' sobre as palmas do nopal exemplares da fêmea prestes a se multiplicar; cerca de 2 meses mais tarde, quando as fêmeas dos pequenos insetos haviam atingido a fase adulta, eram 'varridas' com pincéis para uma vasilha ou pano e, em seguida, mortas por mergulho em água quente (seguida de secagem ao sol) ou através da torrefação. A qualidade do corante obtido da cochonilha silvestre era reputada como a mesma da cochonilha fina, ainda que a quantidade fosse menor. A cochonilha fina ou cultivada encontrava-se principalmente em Oaxaca, Puebla, Tlaxcala e suas vizinhanças, enquanto que a chamada silvestre se espalhava por regiões que incluíam o Brasi $1^{14}$.

Buscando manter o monopólio na produção e comercialização de tão cobiçado bem, o governo espanhol impôs pesadas sanções à divulgação das várias etapas do processo de obtenção do corante, assim como buscava impedir a transplantação do cacto e do pequeno animal. Não surpreende, portanto, que diferentes governos e mesmo particulares procurassem conhecer os segredos de sua produção.

Com esse propósito N. J. Thiéry de Menonville (1739-1780) teria se deslocado à América. Chegando a São Domingos, então colônia francesa (atual Haiti), ele faz com que acreditem em seu interesse em herborizar em outras partes e consegue dos representantes espanhóis um passaporte para Havana. De fato, na ilha, ele passa uma boa parte do dia coletando plantas e herborizando, além 


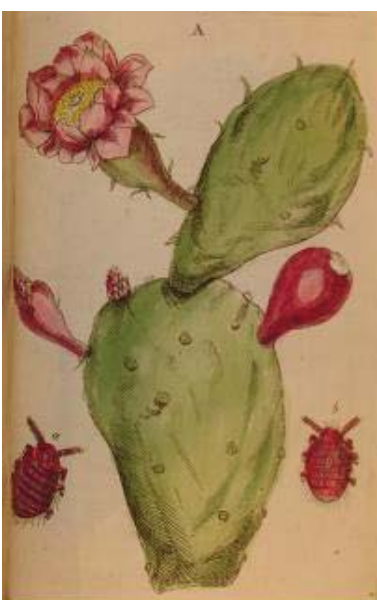

Figura 1. Imagem de O Fazendeiro do Brazil, tomo II, parte 3, "Cultura do Cateiro, e criação da Cochonilha”. Reprodução da ref. 22, exemplar da Biblioteca José e Guita Mindlin

de atender, como médico, pessoas que o procuravam. Ganhando a confiança dos governantes espanhóis, pôde partir para Vera Cruz e depois Oaxaca. Aí procurou aprender todas as etapas do processo de obtenção do corante. Antes de deixar a região comprou - de cultivadores a quem disse que seriam usadas na preparação de um ungüento para a gota -, a preços irrisórios, grandes quantidades de cactos e de insetos, que levou a São Domingos. Essa viagem mereceu de Thiéry de Menonville ${ }^{15}$ uma descrição detalhada de como conduziu os planos para obter os preciosos materiais. Após concretizar uma das compras, ele diz radiante:

"Assim, às cinco horas da manhã eu me encontrava em posse de um belo carregamento de cochonilha, que ninguém me viu comprar, nem embalar; o negro que o vendeu era um homem simples e honesto e os índios que eu paguei bem, recomendando segredo de minha saída matutina, ignoravam de que precioso depósito eu os havia encarregado" ${ }^{\prime \prime}$

Para conseguir levar seu carregamento a São Domingos sem levantar suspeitas, Thiéry de Menonville mandou preparar caixões com fundos falsos e misturou as palmas de cactos coalhadas de cochonilhas a diferentes vegetais. Descreve, um tanto irônico, as risadas provocadas nos guardas espanhóis que achavam estranho que alguém dedicasse tanto de seu tempo a coletar plantas tão comuns. De toda forma, ele fala dos momentos de tensão em que temia ser descoberto e da tristeza de ver muitos dos exemplares de cactos apodrecerem durante a viagem.

Além das memórias da viagem, Thiéry de Menonville compôs um tratado descrevendo as nopaleiras e como cultivá-las, a criação do inseto e a maneira de preparar o corante da cochonilha. Os dois textos foram oferecidos ao Círculo dos Filadelfos, em São Domingos, que se dedicava a áreas como botânica, agricultura, ciências médicas e literatura e mantinha um jardim botânico para cultura do nopal e da cochonilha ${ }^{17}$. Antes de publicar os textos, o Círculo nomeou alguns sócios para verificar se as instruções aí contidas levariam a bons resultados. Confirmadas duas 'colheitas' do inseto em 5 meses, resolveram dar a público, no ano de 1786, o Traité de la culture du nopal et de l'education de la cochenille dans les colonies francaises de l'Amerique, precede d'un voyage a Oaxaca, prometendo a cada subscritor, junto com o "...tratado encadernado [...] plantas do Nopal e da grã de Cochonilha"18.

O trabalho de Thiéry de Menonville teve boa recepção na França merecendo de C.-L. Berthollet um extrato publicado, em 1790, nos Annales de chimie ${ }^{19}$. Além disso, nos Élements de l'art de la teinture, obra que Berthollet publica com seu irmão, são constantes os elogios à coragem, dedicação e persistência de Thiéry de Menonville para concretizar seus planos ${ }^{20}$. Nessa última obra, no capítulo dedicado à cochonilha, encontramos também referências a dados e conclusões do trabalho de Thiéry de Menonville. Assim, debatendo a idéia então geralmente aceita de que a cochonilha devia sua cor ao nopal, "....sobre o qual ela vive e cujos frutos são vermelhos", os irmãos Berthollet acrescentam : “...Thiéri (sic) de Menonville observa que o suco que lhe serve de alimento é esverdeado e que ela [cochonilha] pode viver e se reproduzir sobre espécies de opúncias cujos frutos não são vermelhos"21. Essas observações, são, sem dúvida, muito importantes, pois, por um lado, eliminavam a obrigatoriedade de cultivar o inseto apenas sobre uma espécie de cactos. Por outro, abriam a discussão sobre a origem da cor do corante. Ou seja, transformações mais importantes deveriam acontecer com os materiais que serviam de alimento para a cochonilha, como veremos mais adiante.

O extrato do texto de Thiéry de Menonville, publicado nos Annales de chimie, veio à luz também em português, em 1799, em uma tradução do Frei José Mariano da Conceição Veloso, com o título: Memoria sobre a cultura da Urumbeba e sobre a criação da Cochonilha. Já no ano seguinte, ainda sob os cuidados do Frei Veloso, sai dos prelos um tomo de $O$ Fazendeiro do Brazil, com o texto completo de Thiéry de Menonville, Traité de la culture du nopal et de l'éducation de la cochenille, sendo prometido para o volume seguinte demais textos desse e de outros autores, sempre sobre o mesmo tema ${ }^{22}$

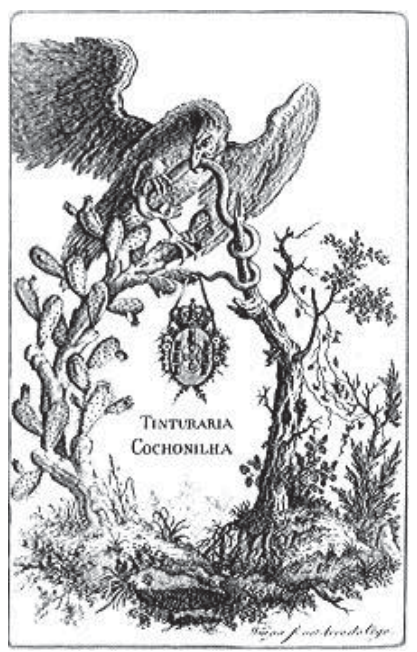

Figura 2. Imagem de O Fazendeiro do Brazil, tomo II, parte 3, "Cultura do Cateiro, e criação da Cochonilha”, onde há referência tanto às armas do México (serpente 'emplumada' sobre o cacto), quanto às de Portugal no século XVIII (centro da imagem). Reprodução da ref. 22, exemplar da Biblioteca José e Guita Mindlin

Essa publicação - assim como outras realizadas pelo Frei Veloso em Lisboa ${ }^{23}$ - destinava-se a promover o desenvolvimento de atividades que pudessem "... produzir hum maravilhoso effeito no commercio Nacional" ${ }^{24}$. No caso da cochonilha, seria possível aproveitar, à beira-mar, as extensas faixas de areia para a plantação do cacto - chamado no Brasil de urumbeba. E, uma vez que “... a latitude do Rio de Janeiro ao Sul, he a mesma do Mexico ao Norte", porque não esperar que no Brasil também se pudesse obter a mesma riqueza que é “... mais segura que as minas de prata: pois se hão muitos paizes, em que este metal abunda, só o Mexico produz a Cochonilha" ${ }^{25}$. 
Essa publicação contém, além da apresentação referida acima, uma introdução escrita por Berthollet, duas secções - "Cactos" e "Da Cochonilha silvestre, e da Mesteca", baseadas nas observações de Thiéry de Menonville - e uma parte escrita por Berthollet denominada: "Comparação da Cochinilha mesteca, da Cochinilha silvestre, e da que se cria em S. Domingos"26. Aí termina o texto traduzido dos Annales de chimie, pois o que se segue foi aposto por Veloso visando a esclarecer alguns pontos que diziam respeito exclusivamente ao Brasil, ou seja: "Methodo de preparar a Cochonilha no Rio de Janeiro" e "Advertencia"27.

$\mathrm{Na}$ secção sobre a cochonilha, não faltam detalhes descritivos da fêmea e do macho, as diferenças entre a cochonilha silvestre e a fina (qual é mais lucrativa), sobre a forma como vivem e se reproduzem os pequenos insetos, a forma de "semeá-los" nos cactos, a maneira mais adequada de "colhê-los" e secá-los. Nessa mesma parte, coloca-se a "... questão: se a Cochinilha fina he da mesma especie da silvestre, aperfeiçoada porém por hum sustento melhor, e pelos cuidados da cultura? ou se ellas formão duas especies essencialmente distintas?" Os argumentos apresentados, não são, segundo o texto, suficientes para resolver a questão, sendo necessárias "novas observações".

Na secção seguinte, de autoria de Berthollet, discutem-se aspectos químicos das experiências realizadas com diferentes cochonilhas, além dos resultados obtidos ao utilizá-las em tingimento ${ }^{28}$. Um dos objetivos de Berthollet ao realizar as análises químicas é determinar as características das 'partes colorantes' e, para isso, faz a digestão, em álcool, do extrato obtido ao evaporar a decocção da cochonilha. As partes colorantes se dissolvem e deixam um resíduo que, analisado 'pelo fogo', dá os “... productos das substancias animais". O "alcohol da Cochonilha" é levado à evaporação, deixando, por sua vez: “... hum resíduo transparente, que he de hum vermelho escuro, e que secco parece uma resina. Igualmente por distillação dá os productos das substancias animaes, o que confirma que esta parte colorante he huma producção animal"29. No texto que estamos analisando, Berthollet não entra em detalhes ao discutir os resultados de suas análises, mas, podemos acompanhar suas idéias abordando outro de seus trabalhos: o Eléments de l'art de la teinture, publicado em 1791 com uma segunda edição revista e aumentada por estudos ${ }^{30}$ sobre o alvejamento de tecidos em 1804. Nessa obra, Berthollet diz que as diferenças entre as 'substâncias' animais e vegetais estariam em que as primeiras: “... contêm, em abundância, um princípio particular, o azoto, [...] que se encontra apenas em pequena quantidade nas substâncias vegetais; $2^{\circ}$. que as substâncias animais contêm muito mais hidrogênio ou base do gás inflamável." Essas diferenças levariam as 'substâncias' animais a produzirem, por destilação, "...muito mais amoníaco, que é um composto de azoto e hidrogênio, [...enquanto as vegetais] dão muito fogo, e mesmo geralmente um ácido" ${ }^{31}$. A conclusão de Berthollet sobre a matéria colorante da cochonilha está, de alguma forma, relacionada com a observação de Thiéry de Menonville sobre a cor do suco do nopal e a da tinta da cochonilha. Ou seja, o suco da planta seria transformado pela cochonilha, perdendo as características dos materiais do reino vegetal e ganhando aquelas do reino animal, segundo as idéias da época ${ }^{32}$.

Outro dos objetivos de Berthollet com suas análises químicas é determinar "... a proporção de partes colorantes, que as decocções de diferentes Cochonilhas continhão", ou seja, a mesteca, a silvestre e a de São Domingos, cujas qualidades ele tem interesse em determinar. A maneira como Berthollet realiza as análises é bem interessante e merece ser descrita. Ele inicia lembrando que a decocção da cochonilha já havia servido para determinar “... a força do Acido muriatico oxigenado [o que denominamos hoje como Cloro] pela quantidade dessa decocção que ele pode destruir". Berthollet pre- tende fazer o inverso, ou seja, usar o "ácido muriatico oxigenado para determinar a proporção de partes colorantes" nas três cochonilhas. Para tanto, preparou três decocções, uma de cada cochonilha, procurando manter constantes as 'circunstâncias'. A cada decocção foi adicionando ácido até que a cor mudasse de vermelho para amarelo. A proporção de ácido utilizado - e, portanto, de partes colorantes - foi: “... 8 para a Cochonilha de São Domingos, 11 para a Cochonilha silvestre do commercio, 18 para a Mesteca",33.

A conclusão de Berthollet não deixaria Menonville muito satisfeito: "A Cochonilha de S. Domingos he, não somente muito inferior á Cochonilha mesteca, mas também á Cochonilha silvestre do México [porém] as tentativas feitas merecem ser prosseguidas, e favorecidas", tendo em conta sua "importância para o commercio" "34.

À época em que Veloso está traduzindo e publicando textos para a colônia portuguesa na América, como é o caso da Memoria sobre a cultura da Urumbeba e sobre a criação da Cochonilha, D. Rodrigo de Souza Coutinho envia Hipólito José da Costa (17741823), nascido no sul do Brasil, para uma viagem de 2 anos à América do Norte ${ }^{35}$. Ele parte em 1798 com instruções de D. Rodrigo para passar pelo México e buscar "conseguir o inseto e a planta da cochonilha e conhecer o método de seu tratamento e preparo e transportá-los para Portugal, procurando iludir a vigilância alfandegária rigorosa dos espanhóis, que proibiam aquela exportação" ${ }^{36}$. O estudioso 'brasileiro' deveria, de certa forma, repetir o que Thiéry de Menonville fizera cerca de 20 anos antes.

De fato, percorrendo o Diário da minha viagem para Filadélfia, texto que permaneceu inédito até 1955 , vê-se em várias partes a referência à cochonilha ${ }^{37}$. Assim, em 11 de março de 1799, ele anota ter conversado com um "habitante de S. Domingos (Mr. Duclos, antigo oficial do Regimento de Cape-Français)" que o havia informado sobre diversos assuntos:

\begin{abstract}
“... este mesmo sujeito me asseverou que em S. Domingos se cultiva a verdadeira cochinilha, e que foi introduzida depois de Mr. Fionville (sic) por um segundo que a trouxe do México; disse-me que eram uns pequenos animais vermelhos como cabeças de alfinetes, no que me parece se engana pois que deviam parecer brancos sendo sempre cobertos com uma espécie de cotão branco" ${ }^{38}$.
\end{abstract}

Fica difícil decidir se Costa tem razão ou não; convém, no entanto, lembrar que no processo de morte do pequeno animal - torrefação ou mergulho em água quente - a cobertura branca pode se desprender, deixando, assim, um material avermelhado. De toda forma, chama a atenção o fato de Costa estar fazendo referência ao "Mr. Fionville" (ainda que a grafia seja diferente ${ }^{39}$ ) de uma maneira que denota intimidade com o nome. Teria ele conhecido, antes de sair de Portugal, o trabalho de Thiéry de Menonville, fosse em português, fosse em francês? É possível que sim, pois Costa esteve envolvido com D. Rodrigo de Souza Coutinho, o principal incentivador da Casa Literária do Arco do Cego, que publicou a tradução das memórias de Thiéry de Menonville. Aliás, Costa substituiu, em sua volta a Portugal, Frei Mariano da Conceição Veloso na direção dessa tipografia ${ }^{40}$. Não temos, entretanto, conhecimento de documentos que permitam uma resposta mais segura.

De toda forma, Costa, em seu Diário, mostra-se empenhado em cumprir os objetivos de sua viagem com relação à cochonilha. Assim, ele aponta ter conhecido, na casa do ministro da Inglaterra, uma pessoa que lhe falou do cobiçado inseto:

“... um almirante espanhol [...] disse-me que a cochonilha se produzia na província de Guaxaba, no México, que apanhavam [...] os bichos rapando-os da planta com uma faca de pau [...] os deitam depois em um vaso grande donde os conduzem a uma bacia d'água 
quente e aí os lançam para os matar, e depois os secam ao sol; não os torram, porque, na panela de torrar, os que ficavam por baixo, se torravam, queimavam, e faziam negros, antes que os de cima estivessem mortos, sendo muito difícil, com este método dar a todos um igual grau de calor" ${ }^{41}$.

Interessante notar que essas informações não parecem avançar em nada o que o estudioso francês dissera sobre a cochonilha, pois Thiéry de Menonville, depois de descrever a maneira como matavam o inseto, diz ser o único método utilizado em $\mathrm{Oaxaca}^{42}$. Se as anotações refletem todo conhecimento que conseguiu obter sobre a cochonilha, não precisaria ter ido tão longe para obtê-lo...

De qualquer maneira, estudos sobre a cochonilha e tentativas de estabelecimento dessa atividade no Brasil já haviam sido realizados anteriormente. Disso dão notícia duas memórias publicadas em $O$ Patriota, periódico impresso no Rio de Janeiro, entre 1813 e 1814. A primeira, "Memória sobre a Cochonilha [...] offerecida aos lavradores Brazileiros", é de autoria de Jacinto José da Silva Quintão. A segunda, "Sumario da Historia do descobrimento da Cochonilha no Brazil", é, de fato, um 'relato' feito por M. J. Henriques de Paiva, de uma memória mais extensa escrita por José Henriques Ferreira ${ }^{43}$. Nas duas memória encontramos referências a uma associação estabelecida sob a proteção do Marquês do Lavradio em 1771 e que teria se dedicado, entre outras questões, a trabalhos sobre a criação do inseto e preparação do corante. Essa associação passaria a ser conhecida como Academia Científica do Rio de Janeiro ${ }^{44}$. Os autores das duas memórias discordam, entretanto, em diversos pontos. Quintão considerava que a cultura da cochonilha havia desaparecido no Brasil por se utilizarem métodos equivocados de propagá-la e pretendia, com seu trabalho, propiciar "as verdadeiras luzes", por ser "o primeiro que com tanta individuação [... faria] conhecer a Cochonilha e sua propagação" 45 .

Paiva responde a Quintão, fazendo publicar, em 1814, no mesmo periódico, o relato do trabalho apresentado por seu irmão, à Academia, de que havia sido o primeiro presidente. Ele considera que Quintão apresentou detalhes inúteis "para quem desconhece a linguagem botanica" - ou seja, os "lavradores Brazileiros" - fazendo referências a uma "classe que já desappareceo do systema naturae de Linneo". Por outro lado, diz Paiva, os métodos de "semear", "criar" e "conseguir abundantes colheitas" de cochonilha não deveriam aparecer em memórias deste tipo, pois "... alem de andar escripto em todos os authores que fallão della, varia conforme a temperatura dos climas." As orientações de seu irmão indicavam que de:

“... todos os methodos praticados no Mexico, se escolheo o melhor, que se foi alterando, segundo as observaçoens, e experiencias, que se hião fazendo, e com effeito conseguirão-se abundantes colheitas da cochonilha tanto no Rio de Janeiro, como noutras partes, onde fora estabelecida" ${ }^{46}$.

Considerando que os dois autores fazem referência à mesma associação que funcionara por alguns anos a partir de 1772, podemos concluir que nesta época já se encontravam, no Brasil, pessoas tentando divulgar os métodos utilizados no México para a produção do corante. Por outro lado, realizavam-se trabalhos em que todas as facetas desta atividade eram consideradas, fossem as de ordem mais 'prática', fossem as 'teóricas' sobre a cochonilha. E, segundo parece, com bons resultados.

Em sua memória, Quintão, retoma um debate já referido anteriormente e faz interessantes observações sobre a relação entre a cor do fruto da cactácea e da cochonilha:

"Reparando na mudança, que fazem os fructos dos cardos, da cor verde para a vermelha, quando chegam á sua perfeita maduração, lembro se será a côr da Cochonilha huma transmudação do suco da planta combinando-se com certos principios de animalisação do bixo, porque os insectos, de que acima fallei, crião-se nos cardos, [e] são de côr vermelha. [...] Talvez a Quimica possa fazer a mesma mudança, que faz a larva no suco da planta : e esta descoberta seria de grande proveito ao Estado" ${ }^{4}$.

Mais uma vez, surge a questão de quais seriam as características dos corantes e como se dariam a transformação do 'suco' dos cacteiros - alimento das cochonilhas - de verde para vermelho. Avançando, porém, o que encontramos nos textos de Thiéry de Menonville e Berthollet, acima discutidos, Quintão imagina que a Química poderia 'imitar' o que a 'natureza', de alguma maneira, realiza ${ }^{48}$.

Paiva, por seu lado, observa que:

“... da cochonilha criada, e apanhada no Jardim Botânico ${ }^{49},[. .$.$] o Vice-Rei$ remettera á Corte de Lisboa huma grande quantidade, assim como huma porção de carmim finissimo, [...] e da Corte se respondera que a dita cochonilha era tão boa como a fina da America hespanhola" ${ }^{50}$.

Paiva deveria ser um bom conhecedor do trabalho com corantes, pois fizera publicar, em 1790, entre suas Memórias de História Natural, de Química, de Agricultura, Artes e Medicina, lidas na Academia das Sciencias, as "Lições elementares da tinturaria das lans". A terceira lição é justamente sobre a "côr incarnada ou vermelha e seus matizes", apresentando detalhes técnicos e químicos da utilização dos corantes, entre eles a cochonilha ${ }^{51}$.

Outro estudioso da cochonilha concorda com a observação de Paiva sobre a qualidade do inseto do Rio de Janeiro. Trata-se de E. Bancroft, que afirma ter analisado essa cochonilha - que lhe chegara via Lisboa - em 1787, obtendo corante de cor tão bela quanto à da "mais fina cochonilha", ainda que o peso fosse a metade ${ }^{52}$. O que está de acordo, ao menos em parte, com a informação de Paiva publicada em $O$ Patriota.

$\mathrm{Na}$ mesma época, outros textos sobre a cochonilha foram publicados em Portugal ${ }^{53}$, mas os discutidos até agora já nos permitem avançar algumas conclusões e mais que isso, enunciar algumas perguntas.

\section{CONCLUSÕES}

Verificamos um grande empenho do governo português em desenvolver atividades lucrativas em suas colônias e, principalmente, no Brasil, onde já não se esperava voltar às grandes cifras em termos de obtenção de ouro e diamantes. Restava aproveitar o que a colônia há tempos dava mostras de poder produzir e teria boa entrada no mercado europeu, com a necessidade crescente de fios e tintas para a indústria que se estabelecia. Assim, são claros os esforços de Dom Rodrigo de Souza Coutinho em, por um lado, fazer publicar - sob a direção do Frei Veloso - textos sobre essas atividades, e, por outro, enviar um 'espião' à América do Norte (com intenção de ir ao México) com a missão de 'descobrir' como melhor se poderiam explorar diferentes atividades no Brasil. Um dos principais objetivos dessa viagem era levar para o reino exemplares das plantas e dos insetos da cochonilha. Notamos, entretanto, um desencontro entre as diversas medidas, pois, por ex., no caso de Hipólito José da Costa, quanto à cochonilha, nada de novo - relativamente ao que se fazia publicar naquele momento em Portugal - aparece em suas notas de viagem, como vimos acima. E, se lembrarmos as análises feitas com a cochonilha produzida no Brasil, essa era considerada de boa qualidade ${ }^{54}$. 
Se pensarmos nas publicações, dificuldades de diversas ordens não permitiram a desejada rota de divulgação do conhecimento e dos textos elaborados. A memória descrevendo o trabalho realizado no Rio de Janeiro à época do Marquês do Lavradio só foi publicada depois de passadas algumas décadas. E, quanto às publicações encabeçadas por Veloso e destinadas ao Brasil, estas também não alcançaram totalmente seus objetivos. Como já lembramos em outros lugares, colocadas à venda no Brasil, encontraram poucos interessados; ficaram apodrecendo em depósitos até serem queimadas, já quase totalmente comidas por traças e cupins ${ }^{55}$.

\section{AGRADECIMENTOS}

À UCL - University College London, M. E. B. Prestes pela leitura atenciosa e correções notadamente quanto às questões de classificação dos seres vivos; F. Possebom pela revisão do texto e, ainda Biblioteca José e Guita Mindlin pela permissão de reprodução das imagens.

\section{REFERÊNCIAS E NOTAS}

1. Entre as espécies utilizadas para extrair o corante estão: Murex trunculus e Murex brandaris.

2. Quermes é o nome dado à fêmea de pulgão ou à excrescência por ela secretada sobre os ramos e galhos de/em algumas espécies de carvalho ou ainda ao próprio corante vermelho; o animal é denominado Coccus ilicis ou Kermes ilicis.

3. A primeira seria a Porphyrophora hamelii, enquanto a segunda, a Porphyrophora polonica.

4. Sandi, M. P.; Becerra, R.; Biodiversitas 2001, 7 ou em http:// www.conabio.gob.mx/otros/biodiversitas/doctos/pdf/biodiv36.pdf, acessada em Fevereiro 2005.

5. Dahlgren, B.; La grana Cochinilla, Univ. Nac. Autónoma de México: México, D. F., 1990, p. 15.

6. Ordenanza de 1620, apud Dahlgren, op. cit., 9.

7. Dahlgren, op. cit., 16 e também os apêndices no final do livro, onde aparecem reproduzidas tabelas com quantidades exportadas em finais do século XVIII; Marichal, C.; "A Forgotten Chapter of International Trade: Mexican Cochineal and the European Demand for American Dyes, 1550-1850", trabalho apresentado na Conference on "Latin America Global Trade and International Commodity Chains in Historical Perspective", Stanford University, 16-17/11/ 2001, versão preliminar disponível em http://www.stanford.edu/group/sshi/ globaltrade2001/marichal.pdf, acessada em Junho 2006, citada com autorização do autor; Lee, R. L.; J. Modern History 1951, 23, 205.

8. Vide, para mais detalhes sobre o texto de Bernardino de Sahagún, Historia general de las Casas de Nueva España, Dahlgren, op. cit., 14; uma lista de outros textos tratando da cochonilha no decorrer dos séculos seguintes pode ser consultada no livro de Dahlgren, p. 335 et seq.

9. Em 1777 Alzate y Ramires finaliza uma memória sobre a cochonilha, publicada pela primeira em 1794, vide estudo introdutório de A. de Ávila Blomberg, "Grana Cochinilla, insecto humanizado", em Alzate y Ramires, Memoria sobre la naturaleza, cultivo y beneficio de la grana, Archivo General de la Nación: México D.F., 2001. Agradecemos à Profa. A. M. Huerta, da Benemérita Universidade Autônoma de Puebla, México, a gentileza de enviar um exemplar dessa publicação facsimilar do manuscrito do autor. Ainda sobre as diversas facetas das atividades de Alzate, vide o volume 6 da série "Estudios de Historia Social de las ciencias Químicas y Biológicas", dedicado totalmente a esse pensador setecentista: Pastrana, P. Aceves (org.); Periodismo científico en el siglo XVIII: José Antonio de Alzate y Ramires, UAM - Unidad Xoxhimilco: México, D.F., 2001.

10. Por isso mesmo denominado como Nopalea coccinellifera.

11. O material de propriedades corantes é hoje denominado de ácido carmínico, $\mathrm{C}_{22} \mathrm{H}_{20} \mathrm{O}_{13}$.

12. Esse animal é classificado de diferentes maneiras, a partir de finais do século XVIII, ora aparece como Coccuc cacti L., ora como Dactylopius coccus Costa; alguns autores explicam a diferença argumentando que Costa e Lineu valeram-se de "diferentes" cochonilhas, provavelmente a fina e a silvestre, para fazerem a classificação; atualmente, o gênero aceito é o Dactylopius, com 9 espécies, algumas presentes na América do Sul; trabalhos mais recentes sugerem mesmo que a cochonilha seria originária do sul das Américas, tendo migrado, através de rotas marítimas, ao norte; vide: Rodríguez, L. C.; Méndez, M. A.; Nyemeyer, H. M.; Antiquity 2001, 75, 73.
13. Dahlgren, op. cit., 12.

14. Ibid.

15. Hesitamos um pouco para escolher a forma como se referir a este autor; a consulta ao catálogo da Bibliotèque Nationale de France nos fez decidir por "Thiéry de Menonville", pois é assim que ele aparece aí mencionado.

16. Menonville, N. J. Thiéry de; Traité de la culture du nopal et de l'éducation de la cochenille dans les Colonies Frrançaises de l'Amérique, précédé d'un voyage a Guaxaca, Cap- Français, Veuve Herbault, 1787, 2 vol.; a citação encontra-se no vol. 1, p. 137; exemplar em microfilme do acervo do Cesima.

17. Sobre o Círculo dos Filadelfos, vide McClellan III, J. E.; "L'historiographie d'une académie coloniale: le Cercle des Philadelphes (1784-1793)", em Bret, P.; Dorigny, M., orgs.; Annales historiques de la Revolution française, número especial: «Sciences et Techniques. Autour de la Révolution française. Approche interdisciplinaire» 2000, 320, 77; vide também, do mesmo autor, Science reorganized: scientific societies in the eighteenth century, Columbia Univ. Press: New York, 1985.

18. Thiéry de Menonville, op. cit. vi-vii; para essa pesquisa estamos utilizando a impressão de 1787; pudemos localizar ainda, em francês, outra de 1789.

19. "Traité sur la culture du nopal, ...", Annales de chimie ou Recueil de mémoires concernant la chimie et les arts qui en dépendent, Masson: Paris, 1790, tomo V, 107-37; o material pertence ao Acervo da Biblioteca de Manguinhos, Seção de Obras Raras A. Overmeer, que reproduziu e enviou a memória para esta pesquisa.

20. Berthollet, C.-L.e A.-B.; Élements de l'art de la teinture, 2 ed., Firmin Didot: Paris, 1804, tomo 2, p. 165 et seq.

21. Ibid., p. 167.

22. Vide Thiéry de Menonville, Memoria sobre a cultura da Urumbeba e sobre a criação da Cochonilha, extrahida por M. Berthollet das Observções feitas por M. Thiery de Menonville e copiada do V. Tomo dos Annaes de Chymica, Of. de Simão Thadeo Ferreira: Lisboa, 1799; J. M. da Conceição Veloso, O Fazendeiro do Brazil, [...] colligido de Memórias Estrangeiras, por Fr. José Mariano da Conceição Velloso, tomo II, parte 3, "Cultura do Cateiro, e criação da Cochonilha”, Off. De João Procópio Correa da Silva: [Lisboa], 1800. Para esta pesquisa tivemos acesso aos exemplares da Biblioteca Nacional do Rio de Janeiro, a partir de cópia microfilmada, digitalizada e depositada no Cesima; já a imagem constante neste artigo foi fotografada do exemplar da Biblioteca José e Guita Mindlin.

23. Durantes os últimos anos do século XVIII e primeiros do século seguinte, Frei Veloso - apoiado por Dom Rodrigo de Souza Coutinho, Secretário de Estado do governo português - esteve à frente de um projeto de publicações destinadas a desenvolver diferentes atividades no reino, sendo uma parte desse material enviada ao Brasil; sobre as atividades de Frei Veloso frente à Tipografia do Arco do Cego, vide Campos, F. M. G., org.; A Casa Literária do Arco do Cego (1799-1801); Bicentenário, INCM: Lisboa, 1999; sobre o envio de diferentes publicações ao Brasil , vide Ferraz, M. H. M.; “A 'fabricação' do salitre no Brasil Colonial: estabelecimento de um corpo documental em arquivos e bibliotecas", em Lértora, C., org.; Rihecqb historia y epistemología de las ciencias: XV reunión internacional instituciones y personalidades trayectoria vital, FEPAI: Buenos Aires, 2005, CD Rom.

24. Essas palavras do Frei Veloso fazem parte da "Apresentação" da tradução do texto de Thiéry de Menonville.

25. Veloso, apresentação da tradução em Thiéry de Menonville, op. cit., iv-vi.

26. A partir daqui, sempre que citarmos o extrato de Berthollet, daremos as referências das duas publicações, a francesa e a portuguesa, referidas respectivamente como "Traité" e Memória; as citações, entretanto, serão feitas a partir da publicação portuguesa, mantendo-se a ortografia original.

27. "Methodo de preparar a Cochonilha no Rio de Janeiro, segundo Stauton, Secretario, e Author da Relação da Embaixada á China do Lord Macartnei", em Thiéry de Menonville, Memória sobre a cultura da Urumbeba, p. 3943; "Advertência", in ibid., p. 45. O primeiro texto foi publicado também separadamente, em Lisboa, por João Procópio Correia da Silva, em 1797; Stauton, ou melhor, Sir George Staunton, acompanhou Lorde Macarteney, chefe da embaixada que o governo britânico enviou à China em 1792; o Rio de Janeiro, estando na rota dessa viagem, mereceu comentários de Staunton, publicados em An Historical Account of the Embassy to the Emperor of China, John Stockdale: Londres, 1797; a referência ao Rio de Janeiro aparece no capítulo V, 37[73]-92, com referência à manufatura do corante da cochonilha.

28. Thiéry de Menonville, Memória, p. 33-38; "Traité”, p. 131-37.

29. Ibid., p. 33 e p. 131. Importante observar que a palavra 'substância' tem, nos textos abordados, um sentido diferente daquele com que a utilizamos hoje; no caso em questão talvez pudéssemos 'traduzir' por 'material'.

30. Berthollet, C.-L.; Eléments de l'art de la teinture, 2 vols, Didot: Paris, 1791, e C.-L. e A.-B. Berthollet; Eléments de l'art de la teinture, avec une description du blanchiment par l'acide muriatique oxygéné, 2 ed. rev., corr. e aum., 2 vols., Firmin Didot: Paris, ano XIII (1804). 
31. Berthollet, C.-L.; Eléments de l'art de la teinture, vol. 1, p. 124; esse mesmo texto, com pequenas modificações aparece na obra publicada em 1804, vol. 1, p. 170; relativamente à produção do ácido, a edição de 1804 acrescenta: "cujas propriedades características são devidas ao oxigênio". Essas mesmas idéias podem ser verificadas no trabalho de A.-L. Lavoisier, quando ele aborda, em seu Traité élémentaire de chimie, a composição dos materiais de origem vegetal e animal. Ou seja, segundo Lavoisier, a análise pelo fogo (aquecimento ou destilação) mostra que “...os princípios verdadeiros constitutivos dos vegetais se reduzem a três [...] hidrogênio, oxigênio e carbono. Eu os denomino constitutivos, pois são comuns a todos os vegetais, e nenhum vegetal existe sem eles". Já notara Lavoisier que alguns vegetais particulares podem apresentar também outros elementos, porém em pequena quantidade, e que são essenciais às plantas que os contêm, como é o caso das plantas crucíferas que apresentam azoto (nosso nitrogênio). Tendo isso em vista, o químico francês argumenta que as matérias animais “...ao serem compostas praticamente dos mesmos princípios das plantas crucíferas, dão na destilação o mesmo resultado; porém como elas contêm mais hidrogênio e mais azoto, produzem mais óleo e mais amoníaco." Vide Lavoisier, A.-L.; Traité élémentaire de chimie, Cuchet: Paris, 1789, p. 132-36.

32. O debate sobre a matéria colorante, o que era, como se formava, como tingia os tecidos, etc., vai ganhar muitos participantes conforme avança o século XIX; essa discussão não se esgota de forma alguma aqui e deixaremos para um outro trabalho aprofundar tais questões.

33. Thiéry de Menonville, Memória, p. 35-6; "Traité", p. 134-5.

34. Ibid., p. 36 e 38; p. 135 e 137.

35. Costa havia recebido o grau em Leis na Universidade de Coimbra em 1798, tendo passado por cursos da Faculdade de Filosofia e da de Matemática, que eram, na verdade, também preparatórios para os cursos jurídicos. Vide Dourado, M.; Hipólito José da Costa e o Correio Brasiliense, Biblioteca do Exército: Rio de Janeiro, 1957, vol. I, p. 43; vide, ainda de Rizini, C., a obra que traz o mesmo título da anterior, Cia. Editora Nacional: São Paulo, 1957, p. 4; a coincidência dos títulos se explica pelo fato de Costa ter publicado o Correio Braziliense (1808-1822), periódico que buscava ser independente do governo estabelecido no Rio de Janeiro. Costa não tinha boas lembranças dos últimos anos passados em Portugal, pois logo após sua volta da América, fora preso, acusado de franco-maçon. Conseguira, entretanto, fugir, estabelecendo-se em Londres, onde justamente publicava o mensário destinado ao Brasil; vide Castro, T.; Hipólito da Costa; Idéias e Ideais, $2^{\mathrm{a}}$. ed. revista e ampliada, Biblioteca do Exército Editora: Rio de Janeiro, 1985, p. 20 et seq.

36. Dourado, op. cit., vol. I, p. 47 et seq.; além de procurar conhecer todo o processo de obtenção do corante da cochonilha, Hipólito José da Costa deveria buscar informações sobre a cultura do tabaco, do cânhamo, trabalhos nas minas de ouro e prata, navegação dos rios, etc.

37. O texto foi encontrado por Alceu Amoroso Lima na Biblioteca de Évora e publicado pela Academia Brasileira de Letras em 1955; para esta pesquisa estamos utilizando uma reimpressão feita pela Livraria Sulina Editora: Porto Alegre, 1974; outro texto de Costa é a "Memória sobre a viagem aos Estados Unidos", relatório encaminhado a D. Rodrigo de Souza Coutinho e publicado na Rev. IHGB 1858, 21, 316.

38. Costa, Diário de minha viagem para a Filadélfia, op. cit., p. 51.

39. Aqui conviria conferir com o manuscrito, pois há referência às dificuldades do copista para transcrever o manuscrito de Costa, assim, é possível que, neste caso, ele tenha se equivocado ao transcrever o nome do estudioso francês; vide "Nota Final" em Costa, Diário de minha viagem, p. 151.

40. Sobre esta tipografia e suas atividades, vide Campos, F. M. G., org.; A Casa Literária do Arco do Cego (1799-1801), op. cit., (nota 23).

41. Costa, Diário de minha viagem para a Filadélfia, op. cit., p. 143-4 e 146 (onde se encontra o texto citado, entre as anotações relativas ao dia 25 de novembro de 1799).

42. Thiéry de Menonville; Memória, p. 28; "Traité,, p. 26.

43. Quintão, J. J. S.; "Memoria sobre a Cochinilha e o methodo de a propagar, offerecida aos lavradores Brazileiros, por hum patriota zelozo, e amante da felicidade publica", O Patriota, segunda subscrição 1813, Outubro, p. 11-19; Paiva, M. J. H.; "Sumario da Historia do descobrimento da Cochonilha no Brazil, e das observaçoens, que sobre ella fez no Rio de Janeiro o Dr. José Henriques Ferreira, Medico do Vice-Rei o Marquez do Lavradio", O Patriota, terceira subscrição, 1814, Janeiro-Feverreiro, p. 313; exemplares da Biblioteca Nacional do Rio de Janeiro; o texto original de José Henriques Ferreira, resumido por Paiva seria a "Disertaçam sobre a Coxonilha, História de seu descobrimento na América Portugueza", Academia das Ciências de Lisboa, Ms Azul, 1030; documentos consultados a partir de microfilme digitalizado no Cesima.
44. No texto publicado em $O$ Patriota, Henriques de Paiva menciona uma "Academia" fundada em 1771 no Rio de Janeiro (com uma primeira sessão em 1772), vide Paiva, op. cit., p. 3 et seq.; uma cópia manuscrita da memória (publicada depois de resumida), traz o que seria o nome completo da associação: "Academia de Medicina, e Historia Natural do Rio de Janeiro", que é conhecida como Academia Científica do Rio de Janeiro; vide Ferreira, "Dissertaçam sobre a Coxonilha", op. cit., fl. 1; Quintão, por seu lado, refere-se, no texto publicado em $O$ Patriota, à "Sociedade Literaria do Rio de Janeiro, fundada sob os auspícios do Marques do Lavradio no segundo anno de seu Vice-Reinado", vide Quintão, op. cit., p. 12, pois ele considerava essa Sociedade (com estatutos de 1786), sucedânea da chamada Academia Científica do Rio de Janeiro; vide registro dos autos da devassa realizada entre 1795-5 contra os membros da Sociedade Literária do Rio de Janeiro, Anais Bib. Nacional, "Devassa ordenada pelo Vice-Rei Conde de Resende”, 1939, 61, 449.

45. Quintão, op. cit., p. 12.

46. Ver Paiva, op. cit., p. 12 e 13.

47. Quintão, op. cit., p. 18.

48. Essa crença na possibilidade de 'imitar' os processos da natureza aparece em outros trabalhos de estudiosos portugueses/'brasileiros' de finais do século XVIII. Em nosso trabalho "A Produção do Salitre no Brasil Colonial”, Quim. Nova 2000, 23, 845, discutimos essa questão relativamente ao possível 'aproveitamento' do nitrogênio do ar para produzir salitre 'artificial'

49. Paiva, neste ponto do texto (p. 11) utiliza a expressão "Jardim Botânico do Rio de Janeiro", enquanto que em outro (p. 5), fala do "Jardim Botânico da Academia"; na versão manuscrita da memória encontramos ainda uma outra denominação para o local onde se cultivava o cacto e criava a cochonilha: "Horto Botânico da Academia"; vide Ferreira, op. cit., fl. 4.

50. Vide Paiva, op. cit., p. 11-12.

51. Obra publicada em Lisboa, Typ. Nunesiana, 1790. A terceira lição aparece entre as p. 193 e 213. As memórias aí publicadas haviam sido "lidas na Academia Real das Sciencias de Lisboa”, conforme vemos no título. Exemplar da Biblioteca Nacional do Rio de Janeiro, a partir de microfilme digitalizado no Cesima. Vide mais detalhes sobre esse autor em Filgueiras, C. A. L; "As vicissitudes da ciência periférica: a vida e a obra de Manoel Joaquim Henriques de Paiva", Quim. Nova 1991, 14, 133.

52. Bancroft; Experimental researches concerning the philosophy of permanent colours; and the best means of producing them, by dying, callico printing, vol. I, T. Cadell, Jun \& W. Davies: Londres, 1794, p. 261.

53. Mesmo em se tratando de textos que interessariam diretamente às atividades desenvolvidas no Brasil, esses eram publicados em Portugal e depois enviados para a Colônia, pois os prelos, assim como outras atividades ligadas aos estudos da natureza, ensino, etc., eram severamente controlados ou proibidos; vide o exemplo da Sociedade Literária do Rio de Janeiro, com seus membros perseguidos e alguns deles encarcerados por vários anos; Alfonso-Goldfarb, A. M.; Ferraz, M. H. M.; "Reflexos [reflexões] sobre uma história adiada: Trabalhos e estudos químicos e pré-químicos brasileiros", Quipu 1988, 5, 345 e, ainda Ferraz, M. H. M.; As ciências em Portugal e no Brasil (1772-1822): O texto conflituoso da Química, Educ/FAPESP: São Paulo, 1997, p. 217 et seq.

54. De volta às análises feitas por Bancroft, podemos dizer que ele pretendia, na verdade, determinar se valeria à pena levar a cochonilha silvestre para a Índia, onde J. Anderson, a serviço da Companhia das Índias Orientais, já conseguira bons resultados na plantação de cactos e precisava, então, dos insetos; de fato, entre 1795 e 1796, em uma série de cartas - muitas delas dirigidas a J. Banks -, o naturalista inglês Anderson mostra já ter o que queria; vide Anderson, J.; Letters \& Co, Boné \& Cooper: Madras, 1796 p. 11; vide, ainda do mesmo autor, An account of the introduction of American cochineal-insects into Hindustan, W. Urquait: Madras, 1795; sobre esses episódios vide Donkin, R. A.; "Spanish Red: An Ethnogeographical Study of Cochineal and the Opuntia Cactus", Trans. Amer. Philos. Soc., nova série, 1977, 67, no. 5, 1-84, esp. 49.

55. Vide nosso livro As ciências em Portugal e no Brasil, op. cit., p.176-7; Moraes, R. B.; Bibliografia Brasileira do período colonial, IEB/USP: São Paulo, 1969, p. 395 e, ainda, “A 'fabricação' do salitre no Brasil Colonial: o estabelecimento de um corpo documental em arquivos e bibliotecas", apresentado no Simpósio Um mapeamento histórico de conhecimentos sobre os compostos de nitrogênio, durante a XV Reunião da RIHECQB, Buenos Aires, 5-7/10/2005, e publicado em Lértora, C., org.; Rihecqb historia y epistemología de las ciencias: XV reunión internacional instituciones y personalidades trayectoria vital, FEPAI: Buenos Aires, 2005, CD Rom. 